\title{
Degradation of $\beta$-casomorphin-7 through in vitro gastrointestinal and jejunal brush border membrane digestion
}

\author{
T. Asledottir, ${ }^{1 *}$ G. Picariello, ${ }^{2}$ G. Mamone, ${ }^{2}$ P. Ferranti, ${ }^{2,3}$ A. Røseth,${ }^{4}$ T. G. Devold, ${ }^{1}$ and G. E. Vegarud ${ }^{1}$ \\ ${ }^{1}$ Faculty of Chemistry, Biotechnology and Food Science, Norwegian University of Life Sciences, 1433 Ås, Norway \\ ${ }^{2}$ Institute of Food Science, National Research Council, 83100 Avellino, Italy \\ ${ }^{3}$ Department of Agriculture, University of Naples Federico II, 80055 Portici, Italy \\ ${ }^{4}$ Department of Internal Medicine, Lovisenberg Diakonale Hospital, 0456 Oslo, Norway
}

\section{ABSTRACT}

This work aimed to study the opioid peptide $\beta$-casomorphin-7 (BCM7) degradation or stability during digestion using human gastrointestinal (GI) juices and porcine jejunal brush border membrane (BBM) peptidases. Synthetic BCM7 was subjected to in vitro digestion by GI fluids obtained from human volunteers for $180 \mathrm{~min}$, and to downstream degradation with porcine BBM vesicles. The BCM7 was sampled at 4 time points over $24 \mathrm{~h}$ after BBM addition. The digests were profiled by HPLC-electrospray ionization mass spectrometry (ESI/MS) to monitor BCM7 during GI digestion, and intact BCM7 through BBM digestion was quantified by reverse-phase (RP)-HPLC. We found that BCM7 was partly digested with human GI enzymes, as 3 proteolytic fragments in addition to $\mathrm{f}(60-66)$ YPFPGPI were detected: $\mathrm{f}(62-66)$ FPGPI, f(60-65) YPFPGP and f(61-66) PFPGPI. The RPHPLC analysis revealed that $42 \%$ of the initial peptide was degraded after only $2 \mathrm{~h}$ of BBM digestion, and as much as $79 \%$ was degraded after 4-h digestion with supplementation of BBM. In conclusion, this study showed that most of BCM7 was degraded during GI and BBM digestion, although a small amount (5\%) was still detected after 24-h digestion. It remains to be studied whether the small amount of intact BCM7 detected after in vitro digestion is transported via active transceptors in the human intestinal epithelial cells and enters blood circulation.

Key words: $\beta$-casomorphin- 7 , in vitro digestion, brush border membrane, bioaccessibility

\section{INTRODUCTION}

The potential bioactivity of $\beta$-casomorphins was postulated as early as the 1970s, based on their

Received April 9, 2019.

Accepted May 24, 2019.

*Corresponding author: tora.asledottir@nmbu.no structural similarity to endogenous opioid peptides. $\beta$-Casomorphins, which are $\beta$-CN-derived sequences of varying length starting from the 60th-position tyrosine (Y) amino acid residue, share the N-terminal $\mathrm{Y}$ and the aromatic phenylalanine $(\mathrm{F})$ in the third position of the sequence. Because of this peptide structural motif, irrespective of length, BCM are ligands of brain $\mu$-type opioid receptors, displaying agonist properties (Nagpal et al., 2011). The opioid peptide $\beta$-casomorphin-7 (BCM7) is encrypted in the native sequence of bovine $\beta-\mathrm{CN}$ at position $60-66$. The presence of proline $[\mathrm{P}$; histidine $(\mathrm{H})$ in $\mathrm{A} 1$ variant] at the 67 th position of the A2 variant appears critical to prevent the proteolytic release of BCM7 and its shorter derivatives (Hartwig et al., 1997). Several studies suggest that the opioid peptide BCM7 can be linked to the development of noncommunicable diseases such as cardiovascular disease, diabetes, and gut inflammation (Tailford et al., 2003; Ul Haq et al., 2014; Chia et al., 2018).

The opioid effects of BCM7 have been demonstrated in vivo, upon intraperitoneal or intracerebellar administration (Lin et al., 1998; Dubynin et al., 2008). However, to exert any action in the central nervous system after oral administration, the milk-derived peptides must first survive proteolytic cleavage after their release from $\beta-\mathrm{CN}$; second, they must be absorbed through the intestinal epithelium, enduring both brush border membrane (BBM) and plasma peptidases; and, third, they must be able to cross the blood-brain barrier. It has also been postulated that $\mathrm{BCM} 7$ and related BCM may act locally, at the level of the gastrointestinal (GI) $\mu$-opioid receptors, by impairing GI functions and delaying GI transit time (Pal et al., 2015; Jianqin et al., 2016).

The heptapeptide BCM7 harbors a proline-rich sequence (YPFPGPI) which, in principle, makes it rather resistant to proteases. The tripeptide motif PFP probably confers structural stability and could be the origin of additional immunomodulatory activity of BCM7 (Bonomi et al., 2011). Petrilli and colleagues (1984, 1987) questioned the possible activity of BCM in vivo, 
because BCM were not released by sequential digestion of water buffalo $\beta$-CN with porcine gastro-duodenal proteases and rabbit jejunal BBM peptidases. In line with these conclusions, a panel of experts interrogated by the EFSA (European Food Safety Authority) concluded that clear proof of a deterministic relationship between intake of BCM and biological effects had not been confirmed; additionally, data then available about the digestion stability of BCM were still controversial (EFSA, 2009). Many of the studies reviewed by the EFSA scientific panel were performed with simplified digestion models, which might not simulate in vivo human physiology. However, Boutrou et al. (2013) detected and quantified BCM7 in human jejunal effluent after CN ingestion, and its amount was considered compatible with an in vivo opioid agonist activity, based on in vitro half-maximal inhibitory concentration $\left(\mathbf{I C}_{50}\right)$ of BCM7 reported elsewhere (Yoshikawa et al., 1994). Also, more recently, the standardized in vitro digestion model (Minekus et al., 2014) was experimentally compared with in vivo digestion data from the human jejunum, which confirmed the similarities between the models at the peptide level for the digestion of a casein fraction (Sanchón et al., 2018). In the milk protein digest obtained from a physiologically relevant in vitro model of GI-jejunal BBM sequential digestion, BCM7 was consistently detected (Picariello et al., 2015). A fragment of BCM7, namely f(60-64) BCM5, was identified in blood serum of human babies whose mothers consumed bovine milk (Wasilewska et al., 2011). Considered a potent opioid peptide, in theory BCM5 could be released from BCM7 during GI digestion.

Previous studies by the present authors showed that BCM7 was released from $\beta-\mathrm{CN}$ variants $\mathrm{A} 1, \mathrm{~A} 2$, and I during GI digestion with human enzymes (Asledottir et al., 2017). Consequently, this work aimed to study the degradation or stability of BCM7 during in vitro digestion with human GI fluids. Further, we aimed to evaluate the bioaccessibility of BCM7 after BBM digestion with porcine jejunal BBM peptidases and to estimate the possibility of BCM7 exerting local effects at the level of the GI opioid receptors. The degradation of BCM7 during GI digestion was monitored by high-performance liquid chromatography-electrospray ionization tandem mass spectrometry (HPLC-ESIMS/MS), and the peptide remaining intact after BBM digestion was quantified by reverse-phase (RP)-HPLC.

\section{MATERIALS AND METHODS}

\section{In Vitro Gastrointestinal Digestion of BCM7 with Human Enzymes}

The experimental design is illustrated in Figure 1. We purchased BCM7 from Thermo Fisher Scientific (Waltham, MA). Gastrointestinal digestion of BCM7 was performed according to the INFOGEST consensus model with some modifications (Minekus et al., 2014). Human GI juices were collected according to Ulleberg et al. (2011), and the pepsin and trypsin activities in the intestinal juices were assayed according to Minekus et al. (2014). Digestion was carried out in parallels with $0.5 \mathrm{~mL}$ of BCM7 dissolved in distilled $\mathrm{H}_{2} \mathrm{O}(4 \mathrm{mg} / \mathrm{mL})$. Digests were sampled after 180-min incubation with 60min gastric digestion and 120-min intestinal digestion, according to Asledottir et al. (2017). Before inhibition of enzyme activities in the GI digest by addition of 5 $\mathrm{m} M$ Pefabloc (Sigma-Aldrich, St. Louis, MO), aliquots of the GI digest were removed for further digestion by $\mathrm{BBM}$ peptidases. The samples were stored at $-20^{\circ} \mathrm{C}$ until HPLC-ESI-MS/MS analysis.

\section{In Vitro Brush Border Membrane Digestion of BCM7 GI Digest with Porcine Jejunal Membrane Peptidases}

After resuspension in a solution of $0.3 \mathrm{M}$ mannitol at protein concentration $1 \mu \mathrm{g} / \mu \mathrm{L}, \mathrm{BBM}$ vesicles were purified from pig jejunum and characterized according

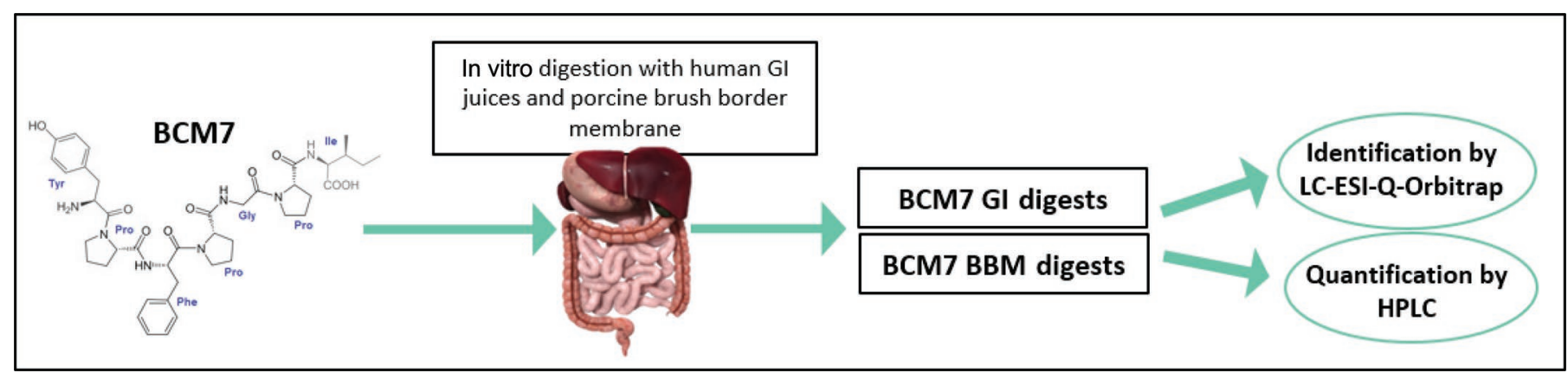

Figure 1. Experimental overview: $\beta$-casomorphin-7 (BCM7) digested with human gastrointestinal (GI) juices for 180 min and with porcine jejunal brush border membrane (BBM) for $24 \mathrm{~h}$. Digests were analyzed by liquid chromatography-electrospray ionization-quadrupole (LCESI-Q) for identification of peptides and by reverse-phase (RP)-HPLC for relative quantification of intact BCM7. 
to Picariello et al. (2015). The aminopeptidase N activity was $879 \mu \mathrm{U} / \mu \mathrm{L}$, determined by spectrophotometric assays using L-leucine $p$-nitroanilide as the substrate (Sigma-Aldrich). Total peptidase activity, determined by RP-HPLC using angiotensin-I (Sigma-Aldrich) as the substrate, was 1,018 $\mu \mathrm{U} / \mu \mathrm{L}$ (Picariello et al., 2015). One unit is defined as the hydrolysis of $1 \mu \mathrm{mol}$ peptide bond per minute. An aliquot of the GI digests of BCM7 (with no addition of protease inhibitor) was incubated at a peptidase-to-substrate ratio of 1:70 (w:w), that is $1.4 \mu \mathrm{L}$ of $\mathrm{BBM}$ vesicles per $100 \mu \mathrm{g}$ of peptide substrate. These figures are roughly consistent with the approximately $13 \mu \mathrm{U} / \mu \mathrm{L}$ peptidases-to-substrate ratio (peptide substrate at concentration of $1 \mu \mathrm{g} / \mu \mathrm{L}$ ) used in physiologically relevant simulated jejunal digestion (Shan et al., 2002). Digests were sampled at 0, 2, 4, and $24 \mathrm{~h}$. At $2 \mathrm{~h}$ of incubation, BBM was supplemented (double amount) to the digestion mixture because the activity of BBM hydrolases tend to decrease over time (Hooton et al., 2015). The experiment was performed in parallels as 2 independent digestions, and the BBM digests were immediately injected in the RP-HPLC for quantification.

\section{Monitoring GI Digestion of BCM7 by HPLC-ESI-MS/MS}

The GI digests were profiled by HPLC-ESI-MS/MS to monitor degradation of BCM7 after 180 min of digestion. Before analysis, GI digests were purified using reverse-phase C18 spin columns (Thermo Fisher), which were placed in clean 1.5-mL Eppendorf tubes (Millipore, Billerica, MA) and centrifuged for $1 \mathrm{~min}$ at 1,500 $\times g$ for each of the elution steps. Briefly, digests $(100 \mu \mathrm{L})$ were loaded onto the $\mathrm{C} 18$ resin previously equilibrated with aqueous $5 \%$ (vol/vol) acetonitrile/0.1\% trifluoroacetic acid (TFA). Peptides were extensively washed with aqueous $5 \%$ (vol/vol) acetonitrile/0.1\% TFA (200 $\mu \mathrm{L}, 3$-fold) and finally eluted with $40 \mu \mathrm{L}$ of $70 \%$ acetonitrile/0.1\% TFA. The eluate was 10 -fold diluted with $0.1 \%$ (vol/vol) formic acid and separated with an Ultimate 3000 ultra high-performance liquid chromatography instrument (Dionex, Thermo Fisher) on line, coupled with a Q-Exactive Orbitrap mass spectrometer (Thermo Fisher). For the HPLC separation, peptides in the digests (arising from approximately $0.1 \mathrm{ng}$ of initial BCM7) were loaded onto a 5-mm long, 300- $\mu \mathrm{m}$ internal diameter pre-column (LC Packings/Dionex/Thermo Fisher, San Jose, CA) using auto-sampler and separated by an EASY-Spray PepMap C18 column (2- $\mu \mathrm{m}$ particles, $15 \mathrm{~cm}$ long $\times 75-\mu \mathrm{m}$ inner diameter $) 3-\mu \mathrm{m}$ particles, 100- $\AA$ pore size (Thermo Fisher). Eluent A was $0.1 \%$ formic acid (vol/vol) in ultra-purified water; eluent B was $0.1 \%$ formic acid ( $\mathrm{vol} / \mathrm{vol}$ ) in acetonitrile.
The column was equilibrated at $5 \%$ eluent B. Peptides were separated applying a 4 to $40 \%$ gradient of B over $45 \mathrm{~min}$, at a flow rate of $300 \mathrm{~nL} / \mathrm{min}$. The mass spectrometer operated in data-dependent mode and all MS1 spectra were acquired in the positive ionization mode with a 1600 to $200 \mathrm{~m} / z$ scan range at a resolving power of 70,000 full width at half maximum (FWHM). Tandem MS fragmentation spectra were obtained at a resolving power of 17,500 FWHM. To prevent repeated fragmentation of the most abundant ions, a dynamic exclusion of $10 \mathrm{~s}$ was applied. Mono-charged ions were included in the fragmentation, whereas main interferent peaks were excluded through a hand-built exclusion list. Spectra were processed using Xcalibur Software version 3.1 (Thermo Fisher). Identification of peptides generated through hydrolysis of BCM7 was manually validated with the aid of the GPMAW version 6.0 (Lighthouse Data, Odense, Denmark). The HPLC-ESIMS/MS analyses were run in duplicate. The potential bioactivity of all peptides identified after in vitro GI digestion of BCM7 was predicted and scored using PeptideRanker (http://distilldeep.ucd.ie/PeptideRanker/; Mooney et al., 2012). Scores above 0.5 were considered as possible bioactive peptides.

\section{Relative Quantification of Intact BCM7 by RP-HPLC}

Degradation of BCM7 during digestion with BBM peptidases was quantitatively determined by RP-HPLC using an HP1100 modular system (Agilent Technologies, Santa Clara, CA) equipped with a C18 RP column of $2.0 \mathrm{~mm}$ (internal diameter) $\times 250 \mathrm{~mm}$ (length) with a $4-\mu \mathrm{m}$ particle diameter (Phenomenex, Torrance, CA). Peptides were separated with a 5-60\% gradient of solvent B over 60 min after 5 min of elution at $5 \%$ B. Solvent A was $0.1 \%$ (vol/vol) TFA in water; solvent B was $0.1 \%$ (vol/vol) TFA in acetonitrile. Effluents were monitored using a multi-wave UV detector, at 214 and $280 \mathrm{~nm}$. Approximately $0.5 \mu \mathrm{g}$ of the pure peptide or of the peptide digests was injected for each run. Four time points ( $\mathrm{t}=0,2,4$, and $24 \mathrm{~h})$ were analyzed in duplicate, and peaks were integrated using the Chemstation Agilent (Version 10.7) furnished with the chromatographer. Intensity of BCM7 at time zero $(t=0)$ was set as $100 \%$ intact peptide, and concentration of BCM7 through BBM digestion was relatively quantified based on intensity peaks at $214 \mathrm{~nm}$. Values were presented as the mean of 2 determinations.

\section{RESULTS AND DISCUSSION}

Use of gastric and duodenal aspirates from healthy human volunteers increases the physiological relevancy of the GI digestion model compared with a simulated 
digestion performed with artificially reproduced fluids. Thus, to monitor BCM7 degradation or stability under ex vivo pseudophysiological conditions, the peptide was sequentially incubated with human gastric and duodenal aspirates. Following simulated digestion, unhydrolyzed BCM7 was detected, and 3 proteolytic fragments were observed by MS and MS/MS (Figure 2). The fragments $\mathrm{f}(61-66)$ PFPGPI and $\mathrm{f}(62-66)$ FPGPI were identified with $0.7 \%$ and $15.1 \%$, respectively, of the ion signal intensity compared with intact f(60-66) BCM7. Another fragment identified with $3.2 \%$ of the ion intensity was $\mathrm{f}(60-65)$ YPFPGP, arising from carboxypeptidase-mediated removal of C-terminal isoleucine (I). In this case, the relative signal intensity provides a rough estimate of the peptides surviving hydrolysis. In fact, the signal intensity generally is not reliable for accurate quantitation, due to sequence-dependent ionization efficiency. For this reason, hydrolytic products of BCM7 were more accurately quantified by RP-HPLC with UV detector (RP-HPLC-UV).

The opioid-binding motif of BCM7 is the N-terminal $\mathrm{Y}$ and the aromatic $\mathrm{F}$ in the third position of the sequence (Figure 3). This suggests that hydrolyzed BCM7 could bind to opioid receptors as long as the N-term is intact. When performing a prediction of bioactivity using PeptideRanker, both BCM7 hydrolysates with $\mathrm{N}$ - and C-term cleaved off exceeded the 0.5 threshold with scores above 0.9 , indicating bioactivity (Table 1 ). This demonstrates that several other peptide fragments deriving from BCM7 could exert a biological effect. Bioactive peptides across different functional classes share some generic features that PeptideRanker uses to predict bioactivity of peptides. This tool is therefore a good approach to identify previously unknown possible bioactives. However, the PeptideRanker tool is not able to predict the degree of bioactivity. It should also be mentioned that the authors and developers of the server noted that there was no clear relation between predicted scores and dipeptidyl peptidase IV (DPPIV) inhibitory properties of some tripeptides when tested in vitro (Nongonierma et al., 2014).

To mimic the final stage of human GI digestion, the GI digests were incubated with BBM enzymes. Intestinal peptidases are omitted in most in vitro simulated digestion models, primarily because consensus about their use is still lacking. Nevertheless, there is no doubt that BBM hydrolases, as both membrane-bound enzymes and vesicles shed into the periapical space of enterocytes contribute heavily to degradation of food components in the pre-absorptive phases. To simulate jejunal digestion, porcine BBM vesicles, which are relatively stable and more easily available, were used as a surrogate of the human counterparts. In general, the panel of digestive enzymes and, in particular, the peptidase activity of porcine BBM vesicles, does not significantly differ from that of the human equivalent (Picariello et al., 2016).

To quantitatively assess the disappearance of BCM7 upon simulated jejunal BBM degradation, digests were analyzed by RP-HPLC at varying time points during digestion. After $2 \mathrm{~h}$ of incubation, $42 \%$ of the initial BCM7 ( $\mathrm{t}=0$ ) was degraded (Figure 4$) ; 79 \%$ of BCM7 was hydrolyzed after 4-h digestion and BBM supplementation. In spite of a substantial susceptibility to hydrolysis, $5 \%$ of intact BCM7 was detectable after 24 $\mathrm{h}$ of BBM incubation.

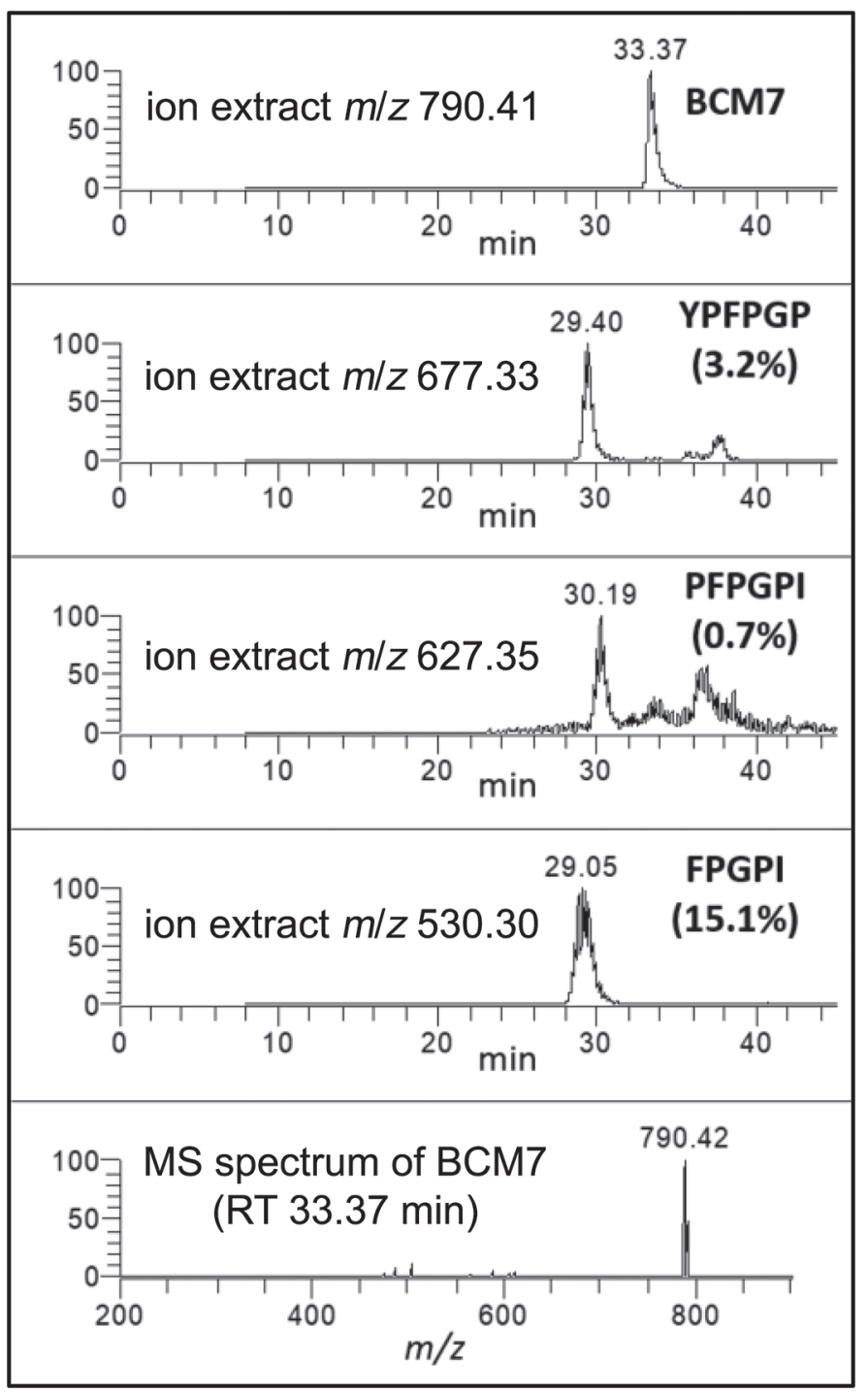

Figure 2. Liquid chromatography (LC)-MS spectra of human gastrointestinal (GI) digests of $\beta$-casomorphin-7 (BCM7) and identification of the main proteolytic fragments. Percentage of the ion signal intensity for each proteolytic fragment is indicated. $\mathrm{RT}=$ retention time. 


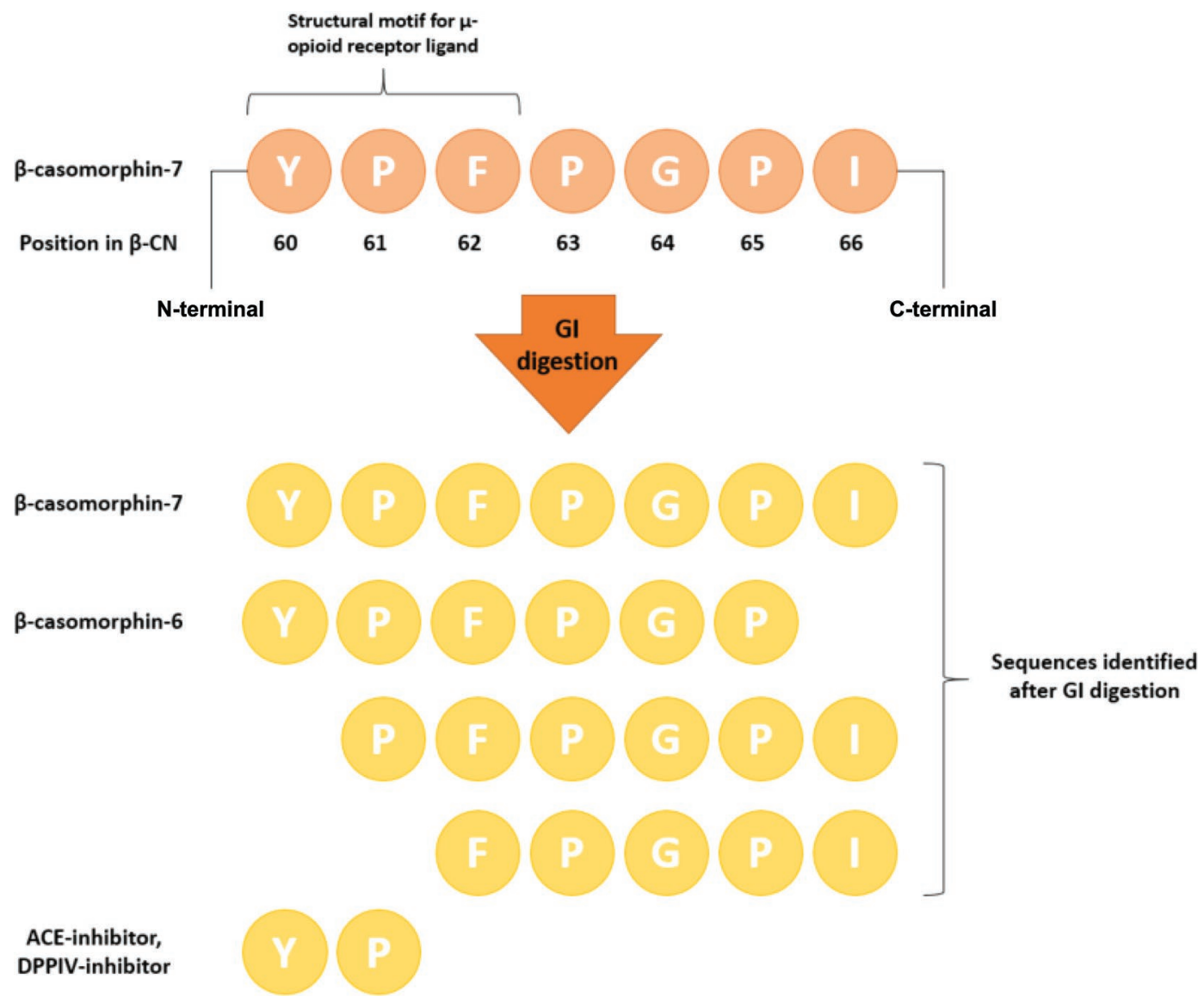

Figure 3. Sequence overview of $\beta$-casomorphin-7 and hydrolysates identified by high-performance liquid chromatography-electrospray ionization tandem mass spectrometry (HPLC-ESI-MS/MS) analysis after in vitro gastrointestinal (GI) digestion with human GI fluids. ACD-inhibitor $=$ angiotensin-converting-enzyme inhibitor; DPPIV-inhibitor = dipeptidyl peptidase IV inhibitor.

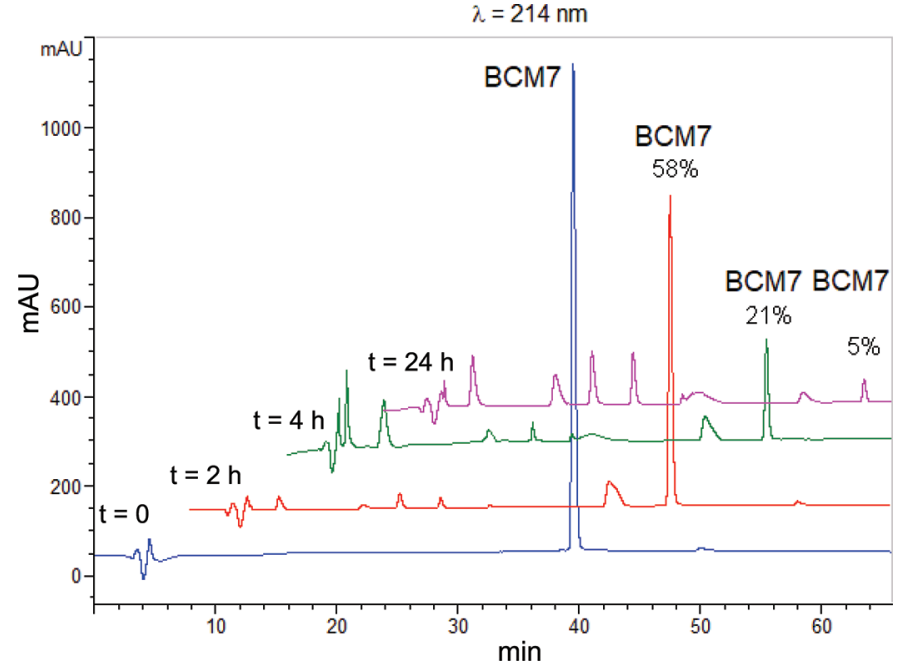

Figure 4. Reverse-phase (RP)-HPLC chromatogram of $\beta$-casomorphin-7 (BCM7) subjected to digestion by brush border membrane (BBM) from 0 to $24 \mathrm{~h}$. Porcine BBM was added twice, at $0(\mathrm{t}=0)$ and $2 \mathrm{~h}(\mathrm{t}=2 \mathrm{~h})$ of incubation. Peak illustrating BCM7 at time 0 was set at $100 \%$. After 24 -h incubation, $5 \%$ of BCM7 remained intact. Values are presented as mean of 2 replicates.
Based on quantification of BCM7 released from in vitro digestion of bovine milk with different genetic variants of $\beta$-CN (Asledottir et al., 2018), bioaccessibility of intact BCM7 through BBM digestion upon ingestion

Table 1. Prediction of bioactive peptides based on scores obtained from PeptideRanker; peptides identified after gastrointestinal digestion of $\beta$-casomorphin-7 (BCM7) were included for prediction analysis

\begin{tabular}{lcl}
\hline $\begin{array}{l}\text { Peptide } \\
\text { sequence }\end{array}$ & $\begin{array}{c}\text { Score }^{1} \\
\text { (PeptideRanker) }\end{array}$ & $\begin{array}{l}\text { Name of } \\
\text { peptide/bioactivity }\end{array}$ \\
\hline FPGPI & 0.951 & \\
YPFPGP & 0.948 & BCM6 \\
PFPGPI & 0.939 & \\
YPFPGPI & 0.917 & BCM7 \\
YP $^{3}$ & 0.739 & ACE inhibitor, DPP-IV inhibitor \\
\hline
\end{tabular}

${ }^{1}$ Peptides with scores above 0.5 are considered bioactive. Peptide Ranker (http://distilldeep.ucd.ie/PeptideRanker/).

${ }^{2} \mathrm{BCM} 6=\beta$-casomorphin- 6 ; ACE inhibitor $=$ angiotensin-convertingenzyme inhibitor; DPP-IV inhibitor $=$ dipeptidyl peptidase IV inhibitor.

${ }^{3}$ This peptide was not identified but was included in the prediction list because it is the N-term that can been cleaved off from BCM7. 
of one 200-mL serving of retail milk can theoretically be roughly estimated. Considering an A1:A2 ratio in retail milk of 0.4:0.6 (Givens et al., 2013), ingestion of $200 \mathrm{~mL}$ of milk would release $1.50 \mathrm{mg}$ of BCM7. This amount could be used to determine the amount of intact BCM7 after exposure to BBM peptidases. After 2-h and 4-h BBM incubation of BCM7 GI-digests, 58 and $21 \%$ BCM7, respectively, was detected. Translating these relative amounts into concentrations based on the data from Asledottir et al. (2018), this would correspond to $0.87 \mathrm{mg}(2 \mathrm{~h})$ and $0.32 \mathrm{mg}(4 \mathrm{~h})$ of BCM7 accessible at the epithelial surface per $200-\mathrm{mL}$ serving of retail milk ingested. This amount can be considered as the amount of bioaccessible BCM7 for binding to opioid receptors in the gut or available for transport across epithelium and transfer into blood circulation. More than 30 yr ago, Teschemacher et al. (1986) did not find evidence of BCM in human plasma after ingestion of milk or dairy products. However, detection of small amounts of dietary peptides in plasma was technically difficult at the time, and dedicated experiments should be repeated using high-resolution modern methodologies. Furthermore, the degree of absorption is dependent on the permeability of the epithelium and may differ from individual to individual, as secretion of gastrointestinal digestion juices can vary across a relatively wide range (Ekmekcioglu, 2002; Kalantzi et al., 2006; Ulleberg et al., 2011). To this purpose, Boutrou et al. (2013) quantified amounts of BCM7 in jejunal effluents to $4 \mathrm{mg}$ after 2 -h digestion. The quantity was estimated to correspond to $17 \mu M$ BCM7 concentration (based on mean volume of jejunal effluent). The authors argued that this concentration was compatible with in vivo opioid agonist activity, based on in vitro data previously reported by Yoshikawa et al. (1994) in which the $\mathrm{IC}_{50}$ value of $\mathrm{BCM} 7$ was measured to a range of 7 to $100 \mu M$. On the other hand, it should be considered that BCM have opioid receptor affinity and specific activity as low as 250 times less than normorphin (Henschen et al., 1979), which indicates a low probability for BCM to exert any potent biological effects related to opioid activity.

The long-term partial survival of small amounts of BCM7 can be caused by inhibition of DPP-IV in the BBM. A proline-specific peptidase, DPP-IV cleaves $\mathrm{X}-\mathrm{P}$ dipeptides from the N-terminus of polypeptides (Rawlings et al., 2018). If BCM7 is cleaved at the second position from the N-terminal, the peptide FPGPI will be released, generating the bioactive dipeptide YP. This peptide has shown to exert DPP-IV-inhibitory activity in vitro (Nongonierma and FitzGerald, 2014). Moreover, Iwan et al. (2008) observed that BCM7 had a higher permeability coefficient in the presence of diprotin A when transported through Caco-2 monolay- ers. Diprotin A is a potent DPP-IV inhibitor, with an $\mathrm{IC}_{50}$ value of $3.5 \mu M$ (Nongonierma and FitzGerald, 2014), and can therefore restrict further degradation of BCM7 by BBM peptidases. Diprotin A, with its amino acid sequence Ile-Pro-Ile, can be found naturally in the sequence of $\kappa-\mathrm{CN}$ in bovine milk. Considering the tripeptide's potential effect on keeping low amount of BCM7 intact, this could explain why milk with higher $\kappa-\mathrm{CN}$ content generated more BCM7 during digestion of milk with different genetic $\beta$-CN variants (Asledottir et al., 2018). In the mentioned study, $\beta$-CN F-variant milk contained the highest concentration of $\kappa-\mathrm{CN}$, and the digestion of the F-milk generated the highest amount of BCM7. The $\mathrm{F}$ genetic variant of $\beta-\mathrm{CN}$ has an amino acid substitution at position 152, where proline is substituted by leucine. The $\mathrm{F}$ variant also contains histidine in position 67 and is therefore classified as belonging to the A1 family of $\beta-\mathrm{CN}$. A similar pattern was observed for the I-variant milk (belonging to the A2 family with an additional methionine-leucine substitution at position 93): 5 times higher BCM7 was quantified, and the I milk contained almost double amounts of $\kappa-\mathrm{CN}$ compared with the A2 milk. A large number of peptides have been identified in hydrolyzed milk with DPP-IV inhibitory activity. If these peptides are present at the site of epithelial cell absorption, this could result in more intact peptides and a higher degree of absorption of larger peptides (e.g., BCM7). However, this is also dependent on the mechanism of absorption, and the transport of peptides with unique amino acid sequences is very complex (Daniel and Zietek, 2015). Epithelial cell absorption favors transport of amino acids and di- and tripeptides, and absorption of larger peptides is more frequent in the intestines of patients suffering from a leaky gut, elderly patients, and infants (Shani-Levi et al., 2017). In this study, degradation products such as di- and tripeptides and amino acids from BCM7 were not monitored. However, because fragments of hexa- and pentapeptides were identified, it is reasonable to assume that smaller peptide fragments, such as the dipeptide YP and amino acids, are present in the digests after GI and BBM digestion.

\section{CONCLUSIONS}

The current study demonstrated the degradation of BCM7 through GI and jejunal BBM digestion. Fragments of BCM7 with predicted bioactivity, such as $\mathrm{f}(60-65)$ YPFPGP, f(61-66) PFPGPI, and f(62-66) FPGPI, were identified by MS. After 2-h BBM digestion, more than $40 \%$ of BCM7 was degraded, and only small amounts $(5 \%)$ of BCM7 were still intact after 24-h BBM digestion. These findings question the hypothesis of any activity of BCM7 related to opioid effects. However, 
there remains need to establish a dose-effect response of BCM7 at a local level in the GI tract after ingestion of milk or milk products, to determine whether the low amounts of BCM7 in the gut are relatable to any pharmacological effects. Further studies should also aim to evaluate the ability of BCM7 to translocate across the intestinal epithelium and, eventually, to determine its occurrence in blood following a milk-based meal using up-to-date detection methods.

\section{ACKNOWLEDGMENTS}

The authors declare no conflicts of interest.

\section{REFERENCES}

Asledottir, T., T. T. Le, B. Petrat-Melin, T. G. Devold, L. B. Larsen, and G. E. Vegarud. 2017. Identification of bioactive peptides and quantification of $\beta$-casomorphin-7 from bovine $\beta$-casein A1, A2 and I after ex vivo gastrointestinal digestion. Int. Dairy J. 71:98106. https://doi.org/10.1016/j.idairyj.2017.03.008.

Asledottir, T., T. T. Le, N. A. Poulsen, T. G. Devold, L. B. Larsen, and G. E. Vegarud. 2018. Release of $\beta$-casomorphin-7 from bovine milk of different $\beta$-casein variants after ex vivo gastrointestinal digestion. Int. Dairy J. 81:8-11. https://doi.org/10.1016/j.idairyj 2017.12.014

Bonomi, F., R. Brandt, S. Favalli, P. Ferranti, O. Fierro, H. Frøkiær, E. Ragg, and S. Iametti. 2011. Structural determinants of the immunomodulatory properties of the C-terminal region of bovine $\beta$-casein. Int. Dairy J. 21:770-776. https://doi.org/10.1016/j .idairyj.2011.04.012.

Boutrou, R., C. Gaudichon, D. Dupont, J. Jardin, G. Airinei, A. Marsset-Baglieri, R. Benamouzig, D. Tome, and J. Leonil. 2013. Sequential release of milk protein-derived bioactive peptides in the jejunum in healthy humans. Am. J. Clin. Nutr. 97:1314-1323. https://doi.org/10.3945/ajcn.112.055202.

Chia, J. S. J., J. L. McRae, A. K. Enjapoori, C. M. Lefevre, S. Kukuljan, and K. M. Dwyer. 2018. Dietary cows' milk protein A1 betacasein increases the incidence of T1D in NOD mice. Nutrients 10. https://doi.org/10.3390/nu10091291.

Daniel, H., and T. Zietek. 2015. Taste and move: Glucose and peptide transporters in the gastrointestinal tract. Exp. Physiol. 100:14411450. https://doi.org/10.1113/EP085029.

Dubynin, V. A., I. V. Malinovskaya, Y. A. Belyaeva, I. S. Stovolosov, Z. D. Bespalova, L. A. Andreeva, A. A. Kamenskii, and N. F. Myasoedov. 2008. Delayed effect of exorphins on learning of albino rat pups. Izv. Akad. Nauk. Ser. Biol. 35:53-60. https://doi.org/10 $.1134 / \mathrm{s} 106235900801007 \mathrm{x}$.

EFSA (European Food Safety Authority). 2009. EFSA Scientific Report 231: Review of the Potential Health Impact of $\beta$-Casomorphins and Related Peptides. European Food Safety Authority, Parma, Italy.

Ekmekcioglu, C. 2002. A physiological approach for preparing and conducting intestinal bioavailability studies using experimental systems. Food Chem. 76:225-230. https://doi.org/10.1016/S0308 -8146(01)00291-6.

Givens, I., P. Aikman, T. Gibson, and R. Brown. 2013. Proportions of $\mathrm{A} 1, \mathrm{~A} 2, \mathrm{~B}$ and $\mathrm{C}$ beta-casein protein variants in retail milk in the UK. Food Chem. 139:549-552. https://doi.org/10.1016/j .foodchem.2013.01.115.

Hartwig, A., M. Gauly, G. Erhardt, H. Teschemacher, and W. Lehmann. 1997. Influence of genetic polymorphisms in bovine milk on the occurrence of bioactive peptides [beta-caso-morphins]. Pages 459-460 in Proc. Milk protein polymorphism, Palmerston North (New Zealand), Feb. 1997. International Dairy Federation, Brussels, Belgium.
Henschen, A., F. Lottspeich, V. Brantl, and H. Teschemacher. 1979. Novel opioid peptides derived from casein (beta-casomorphins). II: Structure of active components from bovine casein peptone. Hoppe Seylers Z. Physiol. Chem. 360:1217-1224.

Hooton, D., R. Lentle, J. Monro, M. Wickham, and R. Simpson. 2015. The secretion and action of brush border enzymes in the mammalian small intestine. Pages 59-118 in Reviews of Physiology, Biochemistry, and Pharmacology. Springer, New York, NY.

Iwan, M., B. Jarmolowska, K. Bielikowicz, E. Kostyra, H. Kostyra, and M. Kaczmarski. 2008. Transport of micro-opioid receptor agonists and antagonist peptides across Caco-2 monolayer. Peptides 29:1042-1047. https://doi.org/10.1016/j.peptides.2008.01.018.

Jianqin, S., X. Leiming, X. Lu, G. W. Yelland, J. Ni, and A. J. Clarke. 2016. Effects of milk containing only A2 beta casein versus milk containing both $\mathrm{A} 1$ and $\mathrm{A} 2$ beta casein proteins on gastrointestinal physiology, symptoms of discomfort, and cognitive behavior of people with self-reported intolerance to traditional cows' milk. Nutr. J. 15:35. https://doi.org/10.1186/s12937-016-0147-z.

Kalantzi, L., K. Goumas, V. Kalioras, B. Abrahamsson, J. B. Dressman, and C. Reppas. 2006. Characterization of the human upper gastrointestinal contents under conditions simulating bioavailability/bioequivalence studies. Pharm. Res. 23:165-176. https://doi .org/10.1007/s11095-005-8476-1.

Lin, L., M. Umahara, D. York, and G. Bray. 1998. $\beta$-Casomorphins stimulate and enterostatin inhibits the intake of dietary fat in rats. Peptides 19:325-331. https://doi.org/0.1016/S0196-9781(97)00307 -0 .

Minekus, M., M. Alminger, P. Alvito, S. Ballance, T. Bohn, C. Bourlieu, F. Carriere, R. Boutrou, M. Corredig, D. Dupont, C. Dufour, L. Egger, M. Golding, S. Karakaya, B. Kirkhus, S. Le Feunteun, U. Lesmes, A. Macierzanka, A. Mackie, S. Marze, D. J. McClements, O. Menard, I. Recio, C. N. Santos, R. P. Singh, G. E. Vegarud, M. S. Wickham, W. Weitschies, and A. Brodkorb. 2014 A standardised static in vitro digestion method suitable for food: An international consensus. Food Funct. 5:1113-1124. https://doi .org/10.1039/c3fo60702j.

Mooney, C., N. J. Haslam, G. Pollastri, and D. C. Shields. 2012. Towards the improved discovery and design of functional peptides: Common features of diverse classes permit generalized prediction of bioactivity. PLoS One 7:e45012. https://doi.org/10.1371/ journal.pone.0045012.

Nagpal, R., P. Behare, R. Rana, A. Kumar, M. Kumar, S. Arora, F. Morotta, S. Jain, and H. Yadav. 2011. Bioactive peptides derived from milk proteins and their health beneficial potentials: An update. Food Funct. 2:18-27. https://doi.org/10.1039/c0fo00016g.

Nongonierma, A. B., and R. J. FitzGerald. 2014. Susceptibility of milk protein-derived peptides to dipeptidyl peptidase IV (DPPIV) hydrolysis. Food Chem. 145:845-852. https://doi.org/10.1016/ j.foodchem.2013.08.097.

Nongonierma, A. B., C. Mooney, D. C. Shields, and R. J. FitzGerald. 2014. In silico approaches to predict the potential of milk proteinderived peptides as dipeptidyl peptidase IV (DPP-IV) inhibitors. Peptides 57:43-51. https://doi.org/10.1016/j.peptides.2014.04 .018 .

Pal, S., K. Woodford, S. Kukuljan, and S. Ho. 2015. Milk intolerance, beta-casein and lactose. Nutrients 7:7285-7297. https://doi.org/10 $.3390 /$ nu7095339.

Petrilli, P., D. Picone, C. Caporale, F. Addeo, S. Auricchio, and G. Marino. 1984. Does casomorphin have a functional role? FEBS Lett. 169:53-56. https://doi.org/10.1016/0014-5793(84)80288-4.

Petrilli, P., P. Pucci, J. P. Pelissier, and F. Addeo. 1987. Digestion by pancreatic juice of a beta-casomorphin-containing fragment of buffalo beta-casein. Int. J. Pept. Protein Res. 29:504-508. https:/ /doi.org/10.1111/j.1399-3011.1987.tb02277.x.

Picariello, G., P. Ferranti, and F. Addeo. 2016. Use of brush border membrane vesicles to simulate the human intestinal digestion. Food Res. Int. 88:327-335.

Picariello, G., B. Miralles, G. Mamone, L. Sánchez-Rivera, I. Recio, F. Addeo, and P. Ferranti. 2015. Role of intestinal brush border peptidases in the simulated digestion of milk proteins. Mol. Nutr. Food Res. 59:948-956. https://doi.org/10.1002/mnfr.201400856. 
Rawlings, N. D., A. J. Barrett, P. D. Thomas, X. Huang, A. Bateman, and R. D. Finn. 2018. The MEROPS database of proteolytic enzymes, their substrates and inhibitors in 2017 and a comparison with peptidases in the PANTHER database. Nucleic Acids Res. 46(D1):D624-D632. https://doi.org/10.1093/nar/gkx1134.

Sanchón, J., S. Fernández-Tomé, B. Miralles, B. Hernández-Ledesma, D. Tomé, C. Gaudichon, and I. Recio. 2018. Protein degradation and peptide release from milk proteins in human jejunum. Comparison with in vitro gastrointestinal simulation. Food Chem. 239:486-494. https://doi.org/10.1016/j.foodchem.2017.06.134.

Shan, L., Ø. Molberg, I. Parrot, F. Hausch, F. Filiz, G. M. Gray, L. M. Sollid, and C. Khosla. 2002. Structural basis for gluten intolerance in celiac sprue. Science 297:2275-2279.

Shani-Levi, C., P. Alvito, A. Andrés, R. Assunção, R. Barberá, S. Blanquet-Diot, C. Bourlieu, A. Brodkorb, A. Cilla, A. Deglaire, S. Denis, D. Dupont, A. Heredia, S. Karakaya, C. V. L. Giosafatto, L. Mariniello, C. Martins, O. Ménard, S. N. El, G. E. Vegarud, E. Ulleberg, and U. Lesmes. 2017. Extending in vitro digestion models to specific human populations: Perspectives, practical tools and bio-relevant information. Trends Food Sci. Technol. 60:52-63. https://doi.org/10.1016/j.tifs.2016.10.017.

Tailford, K. A., C. L. Berry, A. C. Thomas, and J. H. Campbell. 2003. A casein variant in cow's milk is atherogenic. Atherosclerosis 170:13-19. https://doi.org/10.1016/s0021-9150(03)00131-x.
Teschemacher, H., M. Umbach, U. Hamel, K. Praetorius, G. AhnertHilger, V. Brantl, F. Lottspeich, and A. Henschen. 1986. No evidence for the presence of $\beta$-casomorphins in human plasma after ingestion of cows' milk or milk products. J. Dairy Res. 53:135-138. https://doi.org/10.1017/S0022029900024730.

Ul Haq, M. R., R. Kapila, and V. Saliganti. 2014. Consumption of $\beta$-casomorphins-7/5 induce inflammatory immune response in mice gut through Th2 pathway. J. Funct. Foods 8:150-160. https: //doi.org/10.1016/j.jff.2014.03.018.

Ulleberg, E. K., I. Comi, H. Holm, E. B. Herud, M. Jacobsen, and G. E. Vegarud. 2011. Human gastrointestinal juices intended for use in in vitro digestion models. Food Dig. 2:52-61. https://doi.org/10 .1007/s13228-011-0015-4.

Wasilewska, J., E. Sienkiewicz-Szlapka, E. Kuzbida, B. Jarmolowska, M. Kaczmarski, and E. Kostyra. 2011. The exogenous opioid peptides and DPPIV serum activity in infants with apnoea expressed as apparent life threatening events (ALTE). Neuropeptides 45:189-195. https://doi.org/10.1016/j.npep.2011.01.005.

Yoshikawa, M., H. Suganuma, and M. Takahashi. 1994. Enzymatic release of pro-b-casomorphin-9 and b-casomorphin-9 from bovine b-casein. Pages 38-42 in Casomorphins and Related Peptides: Recent Developments. V. Brantl and H. Teschemacher, ed. VCH, Weinheim, Germany. 